\title{
Onion peel water extracts enhance immune status in forced swimming rat model
}

\author{
Hyun-A Lee', Sang-Jun Han', Sunhwa Hong', Dong-Woo Kim', Gi-Wook Oh', Okjin Kim ${ }^{1,2 *}$ \\ ${ }^{1}$ Center for Animal Resources Development, Wonkwang University, Iksan, Korea \\ ${ }^{2}$ Institute of Animal Experiment \& Efficacy Evaluation, Wonkwang University, Iksan, Korea
}

\begin{abstract}
Onion peel contains a high concentration of quercetin and other flavonoids. In this study, the potential immune-enhancing effects of an onion peel water extract (OPE) supplement were investigated by the rat forced swimming test. OPE was prepared using hot water. Thirty-six male Sprague Dawley rats were fed a pellet diet for 1 week and were then randomly divided into six groups: normal control (NC), forced swimming control (FSC), positive control (quercetin $20 \mathrm{mg} / \mathrm{kg}$ ), and three groups administered 4, 20, or $100 \mathrm{mg} / \mathrm{kg}$ of OPE. Oral drug administration was conducted daily for 4 weeks. All rats, except those of NC group, were forced to swim in water and were considered exhausted when they failed to rise to the water surface to breathe within a 7-s period. Blood lymphocyte counts, immune organ weights, histopathological analysis, and serum interferon (IFN)- $\gamma$, tumor necrosis factor (TNF)- $\alpha$, and interleukin (IL)-12 levels were determined. OPE-treated rats consumed more food and had an increased thymic cortex to medulla ratio than that observed in FSC group rats $(P<0.05)$. The area of the white pulp in the spleens of OPE-treated group rats was increased compared with that in FSC group rats $(P<0.05)$. Furthermore, blood lymphocyte numbers and IFN- $\gamma$, TNF- $\alpha$, and IL-12 concentrations were significantly higher in OPE-fed groups than in FSC group $(P<0.05)$. These results suggest that an OPE supplement can improve the immune status by increasing the number of immune-related cells and specific cytokine levels.
\end{abstract}

Keywords: Allium cepa, onion peel, water extract, immune stimulation, cytokines

Received 24 September 2014; Revised version received 18 October 2014; Accepted 18 October 2014

Among the plant foods, onions (Allium cepa) are one of the richest sources of flavonoids in the human diet. Quercetin is a major flavonol abundant in plant products, particularly in onions, and has been reported to possess antioxidative, anti-inflammatory, and lipid-regulating properties [1-5]. Numerous clinical studies and animal and in vitro experiments have demonstrated that phenolic substances, including quercetin, have important antiinflammatory and anti-obesity properties [3,6,7].

At least 25 different flavonoids have been characterized in onion bulbs and quercetin and its glycosides are the most important ones [8]. The highest concentrations of quercetin found in the onion peel, constituting the outer dry layers of the onion bulb [9]. Quercetin and polyphenol, through a modulation of immune function, have been suggested to be involved in the role played by plant foods in disease prevention [10]. The onion peel ethanol extract was reported to have a strong antioxidant activity with quercetin and polyphenol proposed to be the major components responsible for this effect [10], suggesting the possibility that an onion peel supplement could improve the immune status. However, this possibility has not been studied extensively yet.

This study was performed to investigate the effects of an onion peel water extract (OPE) on the immune status by using the rat forced swimming test. We used a water extract rather than an ethanol extract because of its economical and procedural advantages. The effects of

*Corresponding author: Okjin Kim, Center for Animal Resource Development, Wonkwang University, 460 Iksandae-ro, Iksan, Jeonbuk 570-749, Korea

Tel: +82-63-850-6668; Fax: +82-63-850-7308; E-mail: kimoj@wku.ac.kr

This is an Open Access article distributed under the terms of the Creative Commons Attribution Non-Commercial License (http://creativecommons.org/licenses/ by-nc/3.0) which permits unrestricted non-commercial use, distribution, and reproduction in any medium, provided the original work is properly cited. 
the OPE were evaluated by determining the blood lymphocyte numbers, immune organ weights, histopathological analysis, and the serum levels of the immune-relate cytokines Interferon (IFN)- $\gamma$, Tumor necrosis factor (TNF)- $\alpha$, and Interleukin (IL)-12.

\section{Materials and Methods}

\section{Preparation of OPE}

OPE was prepared with yellow onion peels provided by Samhwa Well-being Co. (Iksan, Korea). The onions had been cultivated and harvested in Iksan, Korea. Following collection, onion peels were washed three times in tap water and were shade-dried. The yield of dried onion peels was $13-14 \%(\mathrm{w} / \mathrm{w})$ as compared to that obtained with fresh peels. The dried onion peels were mechanically crushed with a food crusher (Samnet Food Co., Korea), and their composition was analyzed as described below. The dried onion peels were mixed with distilled water at a concentration of $20 \mathrm{mg} / \mathrm{mL}$, the $\mathrm{pH}$ was adjusted to 6 with phosphate buffer, and extraction was carried out using the Soxhlet method at boiling temperature $\left(100^{\circ} \mathrm{C}\right)$ for up to $30 \mathrm{~min}$. The extract was filtered and concentrated in a rotatory evaporator (BUCHI Rotavapor R-220) under reduced pressure at $65 \pm 5^{\circ} \mathrm{C}$ up to $20 \mathrm{~h}$ to obtain a semisolid material (yield: $14.9 \% \mathrm{w} / \mathrm{w}$ ).

\section{Quercetin, total polyphenol, and total antioxidant content determination}

The total polyphenol content of the OPE was determined by the Folin-Ciocalteu Reagent (Sigma Chemical Co., St. Louis, MO, USA) using the method of Vichaponga et al. [11]. Quercetin levels were measured using a highperformance liquid chromatography (HPLC), as previously described [12]. In brief, the hydrolysis of all glycosides to quercetin aglycone in the samples was analyzed by HPLC. A $0.1 \mathrm{~g}$ onion peel sample was mixed with 40 $\mathrm{mL}$ of $60 \%$ aqueous ethanol and $5 \mathrm{~mL}$ of $6 \mathrm{~N} \mathrm{HCl}$. After refluxing at $95^{\circ} \mathrm{C}$ for $2 \mathrm{~h}$, the hydrolyzed solution was filtered into a $100 \mathrm{~mL}$ flask with $60 \%$ aqueous ethanol. Approximately $10 \mathrm{~mL}$ of the solution was filtered through a $0.45 \mu \mathrm{m}$ filter before injection into the HPLC system. The quercetin concentration in the OPE was quantified using a Hewlett-Packard 1100 series HPLC system (Hewlett-Packard, Palo Alto, CA, USA) with a ZORBAX C18 column $(150 \times 4.6 \mathrm{~mm}, 5 \mu \mathrm{m}, \mathrm{XDB}-\mathrm{C} 18$; HewlettPackard, Palo Alto, CA, USA). Elution was performed using a mobile phase made up of water: $5 \%$ acetic acid:acetonitrile (40:30:30) at a flow rate of $1.0 \mathrm{~mL} / \mathrm{min}$. The UV detector was set at $370 \mathrm{~nm}$. The sample injection volume was $20 \mu \mathrm{L}$. The quantification was extrapolated from a standard curve obtained with pure quercetin (Sigma Chemical Co., St. Louis, MO, USA). The total antioxidant status (TAS) of the OPE was analyzed using a TAS kit (Randox Laboratories Ltd., London, UK), according to the manufacturer's instruction. The assay was performed in duplicate on an automated biochemical analyzer, ChemWell-T (Awareness Technology Inc., Palm City, FL), as per the manufacturer's instructions (Randox Laboratories Ltd.). The analyzer was programmed using a ChemWell-T Assay Editor in the standard assay mode to add $200 \mu \mathrm{L}$ of chromogen (metmyoglobin and $\mathrm{ABTS}^{\circledR}$ ) and $4 \mu \mathrm{L}$ of sample/standard control/distilled water, incubate at $37^{\circ} \mathrm{C}$ for $10 \mathrm{~s}$, and read at $630 \mathrm{~nm}$. This was followed by the addition of $40 \mu \mathrm{L}$ of substrate (hydrogen peroxide in stabilized form), incubation at $37^{\circ} \mathrm{C}$ for exactly $3 \mathrm{~min}$, and measuring absorbance at $630 \mathrm{~nm}$. A standard control (6-hydroxy-2,5,7,8-tetramethylchroman2 carboxylic acid) provided in the kit was used for calibration.

\section{Animals}

Four-week-old specific pathogen-free (SPF) male Sprague-Dawley rats were obtained from Samtaco Co. (Osan, Korea). All rats were kept at the inspecting facility of Wonkwang University (Iksan, South Korea) for 1 week to allow acclimation before experimentation. Thereafter, they were kept in an isolated SPF barrier room under a regulated temperature $\left(23 \pm 1^{\circ} \mathrm{C}\right)$, humidity $(50 \pm 5 \%)$, and light/dark cycle (12/12 h). The rats were fed a sterilized ( $2 \mathrm{M}$ rad radiation) pellet diet (Purina, Seoul, Korea) and had access to sterilized water ad libitum. All studies were performed in accordance with the Guide for Animal Experimentation of Wonkwang University and approved by the Institutional Animal Care and Use Committee of Wonkwang University (WKU12-56). All efforts were made to minimize pain or discomfort to the animals used.

\section{Experimental design}

Following a 1-week adaptation period, 36 rats were randomly divided into six groups: NC (normal control), forced swimming control (FSC), PC (positive control; quercetin $20 \mathrm{mg} / \mathrm{kg}$ ), OPE-4 (OPE $4 \mathrm{mg} / \mathrm{kg}$ ), OPE-20 (OPE $20 \mathrm{mg} / \mathrm{kg}$ ), and OPE-100 (OPE $100 \mathrm{mg} / \mathrm{kg}$ ). All rats received a volume of $10 \mathrm{~mL} / \mathrm{kg}$ vehicle or vehicle with 
OPE via oral administration daily for 4 weeks. Vehicle without OPE was administered to the rats in the FSC and $\mathrm{NC}$ group, rats in the $\mathrm{PC}$ group received vehicle containing $20 \mathrm{mg} / \mathrm{kg}$ quercetin, and rats in the OPE-4, OPE-20, and OPE-100 groups received 4, 20, and $100 \mathrm{mg} / \mathrm{kg}$ OPE, respectively.

\section{Forced swimming test}

We used the rat forced swimming test to evaluate the effect of the OPE on the immune status according to a previous reported method [13]. In brief, the apparatus used in this test was an acrylic plastic pool (width, depth, and length $(\mathrm{cm}): 100 \times 80 \times 100)$ filled with water to a depth of $50 \mathrm{~cm}$. The surface of the tank was clear and smooth to prevent the rats from supporting themselves while swimming. A current was generated in the pool by circulating the water with a pump. The water temperature was maintained at $25 \pm 2^{\circ} \mathrm{C}$ by using a water heater (Aquarium Heater 3615200, EIEIM GmbH \& Co. KG., Germany). Steel washers were attached to the tail of each rat. The washers weighed approximately $4 \%$ of the rat body weight. At the end of the 4-week treatment period, all rats, except those in the NC group, were fasted overnight and were subjected to the forced swimming test. Endurance was defined as the time from placement into the pool until the time that the animal remained submerged in water without movement. Rats underwent the test until they reached exhaustion, i.e., when they failed to rise to the water surface to breathe within a 7$\mathrm{s}$ period.

\section{Body weights and food consumption and organ weights}

Body weights and food consumption of the rats were evaluated during the experimental period with digital weighing scales (IB-3100, Innotem Co., Korea). The thymus and spleen were removed from anesthetized rats immediately after completion of the forced swimming exercise, and their weights measured.

\section{Histopathological analysis}

For histological analysis, the dissected tissues were fixed in $10 \%$ buffered formalin, routinely processed, and embedded in paraffin. Four-micrometer sections were cut using a microtome (Shandon, UK) and stained with hematoxylin \& eosin (H\&E). Thymuses and spleens were first stained with classic $\mathrm{H} \& \mathrm{E}$ and then analyzed using Image analyzer (Focus Technology, Germany).
The ratio of thymic cortex to medulla was determined on whole thymus image slides according to a previous reported method [14]. Briefly, we measured each cortex and medullar thickness in thymus with Image analyzer (Focus Technology). Then, the ratio of thymic cortex to medulla was calculated. We also evaluated the area of the white pulp in the spleens according to Elmore [15]. The areas of the white pulps were measured with Image analyzer and then, the average values were calculated.

\section{Blood cell counts and cytokine analysis}

Immediately after the forced swimming test, blood was collected from the abdominal vein prior to necropsy. Blood lymphocyte numbers were counted using an automatic blood cell counter (LC660 HORIBA, Japan). Blood samples were centrifuged at $3,000 \mathrm{rpm}$ at $25^{\circ} \mathrm{C}$ for 10 min (Micro17TR, Hanil Science Industrial Co., Ltd, Korea). The serum IFN- $\gamma$ and TNF- $\alpha$ levels were determined with a fluorescence kit (Millipore, USA), and the serum IL-12 level was determined with Luminex LX200 (Invitrogen, USA) by using a Microplate Reader VERSA Max (Molecular Devices, USA).

\section{Statistical analysis}

ANOVA (one-way analysis of variance test) was used to compare the data between the groups. All analyses were conducted using the SPSS software (version 12.0, SPSS Inc., Chicago, IL, USA).

\section{Results}

\section{Quercetin, total polyphenol, and total antioxidant content determination}

The amount of total polyphenol of OPE was $34.74 \mathrm{mg} /$ g. Quercetin measurements were done using HPLC and the concentration was $13.50 \mathrm{mg} / \mathrm{g}$. The total antioxidant status was $63.33 \mathrm{mg} / \mathrm{g}$.

\section{Body weight gain and food intake and organ weights}

Table 1 presents the body weights of the rats during the 4-week experimental period. There were no significant differences between the groups. Although not statistically significant, the body weights of the rats in the FSC group were relatively low as compared with those of rats in other groups. Table 2 shows the average amount of food intake (g/day) during the 4-week experimental period. The OPE-treated groups consumed more food than the FSC group since 2 weeks after inoculation $(P<0.05)$. 
Table 1. Body weight changes of OPE and non-OPE-treated rats

\begin{tabular}{lccccc}
\hline \multirow{2}{*}{ Group } & \multicolumn{5}{c}{ Weeks after start of treatment } \\
\cline { 2 - 6 } & 0 & 1 & 2 & 3 & 4 \\
\hline NC & $110.89 \pm 4.60$ & $160.66 \pm 8.66$ & $208.04 \pm 9.29$ & $268.32 \pm 13.84$ & $304.53 \pm 13.84$ \\
FSC & $108.20 \pm 2.15$ & $158.50 \pm 5.25$ & $205.25 \pm 6.20$ & $264.30 \pm 8.50$ & $302.50 \pm 10.25$ \\
PC & $109.18 \pm 4.11$ & $165.25 \pm 7.58$ & $210.80 \pm 6.32$ & $272.80 \pm 11.92$ & $315.05 \pm 10.80$ \\
OP-4 & $104.79 \pm 4.05$ & $158.49 \pm 6.23$ & $215.43 \pm 6.19$ & $275.01 \pm 10.33$ & $314.90 \pm 13.27$ \\
OP-20 & $103.06 \pm 4.06$ & $153.93 \pm 6.83$ & $212.67 \pm 4.94$ & $268.01 \pm 10.18$ & $308.57 \pm 10.86$ \\
OP-100 & $104.84 \pm 4.85$ & $153.3 \pm 7.54$ & $211.70 \pm 8.49$ & $265.01 \pm 12.1$ & $299.89 \pm 12.92$ \\
\hline
\end{tabular}

NC: normal control group, FSC: forced swimming control group, PC: forced swimming control group receiving $20 \mathrm{mg} / \mathrm{kg}$ quercetin, OPE-4: forced swimming test group receiving $4 \mathrm{mg} / \mathrm{kg}$ OPE, OPE-20: forced swimming test group receiving $20 \mathrm{mg} / \mathrm{kg}$ OPE, OPE100: forced swimming test group receiving $100 \mathrm{mg} / \mathrm{kg}$ OPE.

Values are mean $\pm S D$

Table 2. Food consumption changes of OPE and non-OPE-treated rats

\begin{tabular}{lcccc}
\hline \multirow{2}{*}{ Group } & \multicolumn{4}{c}{ Weeks after start of treatment } \\
\cline { 2 - 4 } & 1 & 2 & 3 & 4 \\
\hline NC & $12.06 \pm 0.96$ & $15.07 \pm 0.75$ & $20.73 \pm 0.58$ & $21.52 \pm 0.42$ \\
FSC & $11.05 \pm 0.25$ & $13.20 \pm 0.55$ & $19.50 \pm 0.25$ & $20.25 \pm 0.28$ \\
PC & $14.77 \pm 0.66$ & $16.67 \pm 0.62^{*}$ & $22.59 \pm 0.73^{*}$ & $23.37 \pm 0.76^{*}$ \\
OP-4 & $13.53 \pm 0.71$ & $18.61 \pm 0.32^{*}$ & $23.40 \pm 0.28^{*}$ & $24.30 \pm 0.99^{*}$ \\
OP-20 & $12.06 \pm 0.95$ & $18.13 \pm 0.22^{*}$ & $23.91 \pm 0.76^{*}$ & $24.50 \pm 0.75^{*}$ \\
OP-100 & $13.37 \pm 1.36$ & $17.50 \pm 0.66^{*}$ & $23.39 \pm 0.72^{*}$ & $25.01 \pm 0.65^{*}$ \\
\hline
\end{tabular}

NC: normal control group, FSC: forced swimming control group, PC: forced swimming control group receiving $20 \mathrm{mg} / \mathrm{kg}$ quercetin, OPE-4: forced swimming test group receiving $4 \mathrm{mg} / \mathrm{kg}$ OPE, OPE-20: forced swimming test group receiving $20 \mathrm{mg} / \mathrm{kg}$ OPE, OPE100: forced swimming test group receiving $100 \mathrm{mg} / \mathrm{kg}$ OPE.

Values are mean $\pm S D$

"Significantly different compared with forced swimming control group $(P<0.05)$

Table 3. Organ weights of OPE and non-OPE-treated rats

\begin{tabular}{lcc}
\hline Group & Thymus & Spleen \\
\hline NC & $0.78 \pm 0.04$ & $0.77 \pm 0.05$ \\
FSC & $0.73 \pm 0.07$ & $0.74 \pm 0.07$ \\
PC & $0.80 \pm 0.09$ & $0.77 \pm 0.07$ \\
OP-4 & $0.79 \pm 0.04$ & $0.82 \pm 0.04$ \\
OP-20 & $0.76 \pm 0.05$ & $0.77 \pm 0.04$ \\
OP-100 & $0.73 \pm 0.09$ & $0.76 \pm 0.09$
\end{tabular}

NC: normal control group, FSC: forced swimming control group, PC: forced swimming control group receiving $20 \mathrm{mg} / \mathrm{kg}$ quercetin, OPE-4: forced swimming test group receiving $4 \mathrm{mg} / \mathrm{kg}$ OPE, OPE-20: forced swimming test group receiving $20 \mathrm{mg} / \mathrm{kg}$ OPE, OPE-100: forced swimming test group receiving $100 \mathrm{mg} / \mathrm{kg}$ OPE. Values are mean $\pm S D$

The weights of the spleen and the thymus after the 4week experimental period are shown in Table 3. No significant differences were found in the weights between the different treatment groups. Although not statistically different, the weights of the spleen and the thymus of the FSC group were relatively low as compared with those of the other groups.

\section{Histopathological observations}

The ratio of thymic cortex to medulla was significantly
Table 4. The effects of OPE on the concentration of IFN- $\gamma$, IL12 , and TNF- $\alpha$

\begin{tabular}{lccc}
\hline Group & $\mathrm{IFN}-\gamma(\mathrm{pg} / \mathrm{mL})$ & $\mathrm{IL}-12(\mathrm{pg} / \mathrm{mL})$ & $\mathrm{TNF}-\alpha(\mathrm{pg} / \mathrm{mL})$ \\
\hline NC & $6.5 \pm 0.87$ & $736.9 \pm 100.35$ & $4.4 \pm 0.34$ \\
FSC & $5.3 \pm 0.66$ & $620.5 \pm 107.21$ & $3.8 \pm 0.42$ \\
PC & $6.9 \pm 0.47^{*}$ & $1219.6 \pm 125.58^{*}$ & $5.4 \pm 0.54^{*}$ \\
OP-4 & $7.1 \pm 0.51^{*}$ & $1111.1 \pm 109.31^{*}$ & $5.1 \pm 0.52^{*}$ \\
OP-20 & $7.3 \pm 0.65^{*}$ & $1499.1 \pm 131.63^{*}$ & $5.4 \pm 0.29^{*}$ \\
OP-100 & $7 \pm 0.49^{*}$ & $954.5 \pm 101^{*}$ & $5.1 \pm 0.34^{*}$ \\
\hline
\end{tabular}

NC: normal control group, FSC: forced swimming control group, PC: forced swimming control group receiving $20 \mathrm{mg} / \mathrm{kg}$ quercetin, OPE-4: forced swimming test group receiving $4 \mathrm{mg} / \mathrm{kg}$ OPE, OPE-20: forced swimming test group receiving $20 \mathrm{mg} / \mathrm{kg}$ OPE, OPE-100: forced swimming test group receiving $100 \mathrm{mg} / \mathrm{kg}$ OPE. Values are mean $\pm S D$

"Significantly different compared with forced swimming control group $(P<0.05)$

increased in the OPE-20 group compared with those in the FSC group $(P<0.05$, Figure 1). Also, the area of the white pulp was significantly increased in PC, OPE-4, OPE-20 and OPE-100 group compared with those in the FSC group $(P<0.05$, Figure 2$)$.

\section{Blood cell counts and cytokine analysis}

Blood lymphocyte numbers were significantly higher 


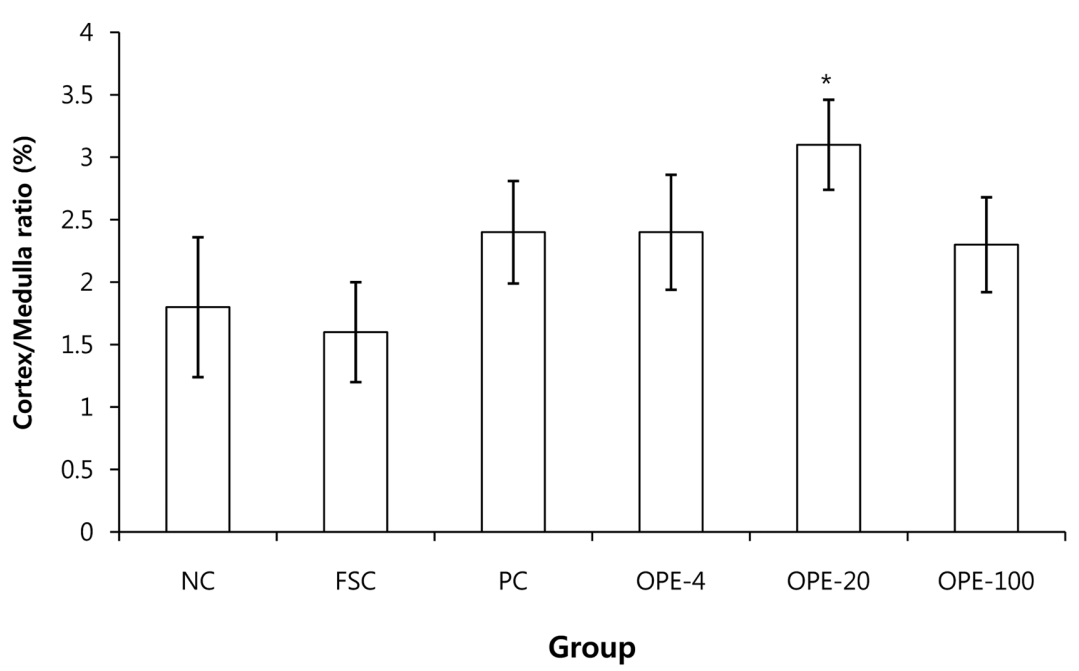

Figure 1. The effect of OPE on the thymic cortex/medulla ratio (\%). NC: normal control group, FSC: forced swimming control group, PC: forced swimming control group receiving $20 \mathrm{mg} / \mathrm{kg}$ quercetin, OPE-4: forced swimming test group receiving $4 \mathrm{mg} / \mathrm{kg}$ OPE, OPE-20: forced swimming test group receiving $20 \mathrm{mg} / \mathrm{kg}$ OPE, OPE-100: forced swimming test group receiving $100 \mathrm{mg} / \mathrm{kg}$ OPE. Values are mean \pm SD. *Statistically significant difference compared with forced swimming control group $(P<0.05)$.

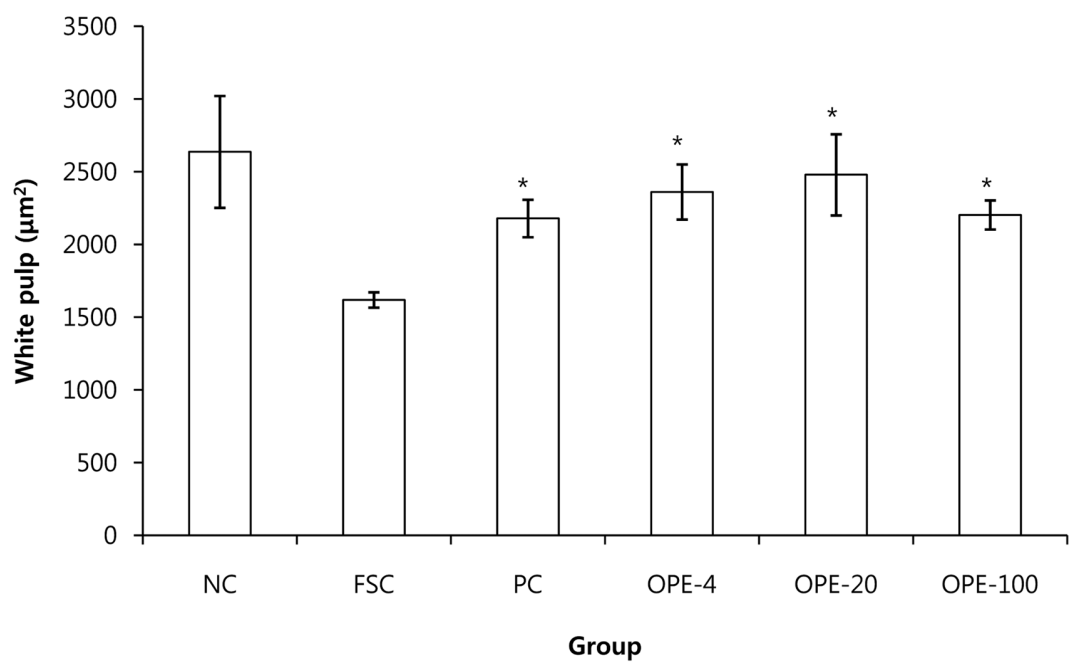

Figure 2. The effect of OPE on the area of spleen white pulp. NC: normal control group, FSC: forced swimming control group, PC: forced swimming control group receiving $20 \mathrm{mg} / \mathrm{kg}$ quercetin, OPE-4: forced swimming test group receiving $4 \mathrm{mg} / \mathrm{kg}$ OPE, OPE-20: forced swimming test group receiving $20 \mathrm{mg} / \mathrm{kg}$ OPE, OPE-100: forced swimming test group receiving $100 \mathrm{mg} / \mathrm{kg}$ OPE. Values are mean $\pm S D$. *Statistically significant difference compared with forced swimming control group $(P<0.05)$.

in the OPE-treated groups than in the FSC group $(P<0.05$, Figure 3). Furthermore, the concentrations of IFN- $\gamma$, TNF- $\alpha$, and IL-12 were significantly higher in the OPE-fed groups as compared with those in the FSC group $(P<0.05$, Figure 3$)$.

\section{Discussion}

Onions are among the most highly consumed vegetables worldwide and contain several kinds of flavonoids, predominantly quercetin, and smaller quantities of kaempferol, isorhamnetin, anthocyanin, and taxifolin [8]. Besides quercetin, onions also contain antioxidants and quercetin derivatives where glycosyl moieties are found at different positions in the molecule [16,17]. Several epidemiologic and animal studies suggest beneficial health effects, including antidiabetic, anticancer, and antifungal activities [18-20], of flavonoids and organosulfur compounds, all of which are abundant in onions [21].

Until now, it had not been reported whether OPE has an anti-fatigue and exercise-enhancing effect. However, 


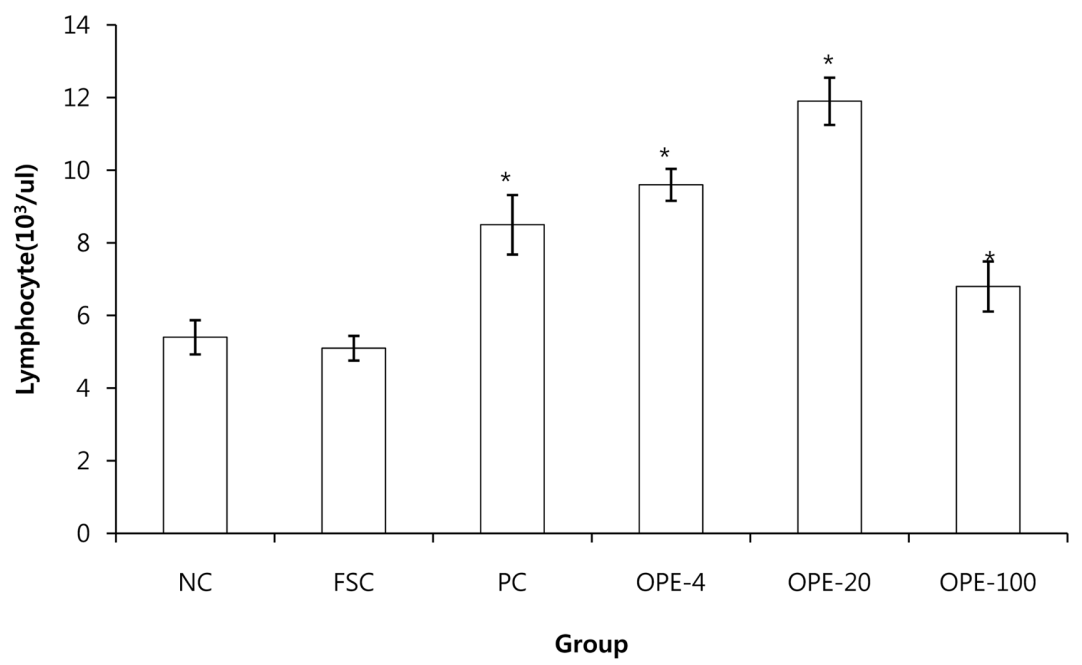

Figure 3. The effect of OPE on lymphocyte counts. NC: normal control group, FSC: forced swimming control group, PC: forced swimming control group receiving $20 \mathrm{mg} / \mathrm{kg}$ quercetin, OPE-4: forced swimming test group receiving $4 \mathrm{mg} / \mathrm{kg}$ OPE, OPE-20: forced swimming test group receiving $20 \mathrm{mg} / \mathrm{kg}$ OPE, OPE-100: forced swimming test group receiving $100 \mathrm{mg} / \mathrm{kg}$ OPE. Values are mean $\pm S D$. *Statistically significant difference compared with forced swimming control group $(P<0.05)$.

in the present study, the maximal exercise performance periods of the rats were used to evaluate the effects of OPE on physical activity. The forced swimming test has been widely used for evaluating physical activity and immune depletion [22-25]. In this study, we used forced swimming test and obtained the results indicated that the administration of OPE may enhance immune status.

Recently, research to discover immune-modulating compounds in natural products is being actively pursued [26-29]. Onion peel contains large amounts of total polyphenols, antioxidants, and quercetin [9]. Previous studies on the effects of onion peel were conducted with ethanol extracts [12,20,30]. Jung et al. [20] used 60\% ethanol extracted OPE, which contained $101.28 \mathrm{mg} / \mathrm{g}$ quercetin. They treated the rats with diet containing 0.5 , or $1 \%$ of OPE. In the present study, we used water extracted onion peel, which contained $13.50 \mathrm{mg} / \mathrm{g}$ quercetin. We inoculated per orally the rats with 4, 20 and $100 \mathrm{mg} / \mathrm{kg}$ respectively. In this study, OPE $20 \mathrm{mg} /$ $\mathrm{kg}$ treated rats revealed most prominent enhancement of the immune status in rats.

TNF- $\alpha$ is produced by several immune cells, such as macrophages and $\mathrm{T}, \mathrm{B}$, and natural killer (NK) cells and modulates not only cell survival but also cell death (apoptosis). It is therefore referred to as a "double-edged sword" [31]. In particular, it is important in regulating inflammation and the host defense in response to bacterial infection [32]. IFN- $\gamma$ is a type II interferon that exerts its effects through its receptors IFN- $\gamma \mathrm{R} 1$ and IFN- $\gamma \mathrm{R} 2$ [33], and activates JAK1, JAK2, and subsequently STAT1 [34]. It was recently approved by the United States Food and Drugs Authority (US FDA) for improving chronic granulomatous disease and malignant osteopetrosis [26]. IL-12 is involved in the differentiation of naive $T$ cells into Th1 cells [35]. It is known as a $T$ cellstimulating factor, which can stimulate the growth and function of $\mathrm{T}$ cells. It stimulates the production of IFN$\gamma$ and TNF- $\alpha$ from T cells and NK cells, and reduces the IL-4-mediated suppression of IFN- $\gamma$ [35]. Abood et al. [36] found that the intake of Tinospora crispa, which contains a high concentration of polyphenols, enhanced the immune status through the stimulation of INF- $\gamma$, IL-6, and IL-8 expression. Cyrtomium macrophyllum (Makino) Tagawa is also rich in polyphenols and the intake of the ethanol extract can improve immune function by enhancing $\mathrm{T}$ and $\mathrm{B}$ cell proliferation responses and macrophage function [37]. In addition, it has been reported that the administration of the polyphenol-rich Brazilian green propolis has a positive effect on the innate and adaptive immunity in aged mice [38].

Generally, water extracts of herbal compounds are advantageous over ethanol extracts from an economical, procedural, and safety point of view [39]. In this study, OPE was obtained by a water extraction method; therefore it could also be useful for the functional food industry. Rats in the OPE-treated groups exhibited higher food consumption and had an increased thymic cortex to medulla ratio than that observed in the rats of the FSC 
group $(P<0.05)$. Furthermore, the area of the white pulp in the spleens of the OPE-fed rats was increased compared with that in the FSC rats $(P<0.05)$. The IFN- $\gamma$, TNF- $\alpha$, and IL-12 levels and blood lymphocyte numbers were significantly increased in the OPE-fed groups than those in the FSC-fed group $(P<0.05)$. We observed the significant increase of cortex/medulla ratio, white pulp, and lymphocytes in the OPE-treated groups. Especially, the increases were most prominent in OPE-20 group. We thought that the optima dose of OPE for the immune enhance may be $20 \mathrm{mg} / \mathrm{kg}$ in rats.

Our results suggest that OPE can enhance immunity by increasing the number of immune-related cells and the concentration of specific cytokines. Considering that the majority of onion peels end up as waste with limited use, this study suggests the potential of a supplementary use of onion peels in the management of physical activity and immune status.

\section{Acknowledgments}

This paper was supported by Wonkwang University in 2014.

Conflict of interests The authors declare that there is no financial conflict of interests to publish these results.

\section{References}

1. Hertog MG, Feskens EJ, Hollman PC, Katan MB, Kromhout D. Dietary antioxidant flavonoids and risk of coronary heart disease: the Zutphen Elderly Study. Lancet 1993; 342(8878): 1007-1011.

2. Lee KH, Kim Y, Park E, Hwang HJ. Effect of onion powder supplementation on lipid metabolism in high fat-cholesterol fed SD Rats. J Food Sci Nutr 2008; 13(2): 1371-1376.

3. Rivera L, Morón R, Sánchez M, Zarzuelo A, Galisteo M. Quercetin ameliorates metabolic syndrome and improves the inflammatory status in obese Zucker rats. Obesity (Silver Spring) 2008; 16(9): 2081-2087.

4. Stewart LK, Soileau JL, Ribnicky D, Wang ZQ, Raskin I, Poulev A, Majewski M, Cefalu WT, Gettys TW. Quercetin transiently increases energy expenditure but persistently decreases circulating markers of inflammation in C57BL/6J mice fed a high-fat diet. Metabolism 2008; 57(1): S39-46.

5. Zern TL, Wood RJ, Greene C, West KL, Liu Y, Aggarwal D, Shachter NS, Fernandez ML. Grape polyphenols exert a cardioprotective effect in pre- and postmenopausal women by lowering plasma lipids and reducing oxidative stress. J Nutr 2005; 135(8): 1911-1917.

6. Hsu CL, Yen GC. Effects of flavonoids and phenolic acids on the inhibition of adipogenesis in 3T3-L1 adipocytes. J Agric Food Chem 2007; 55(21): 8404-8410.

7. Yen GC, Chen YC, Chang WT, Hsu CL. Effects of polyphenolic compounds on tumor necrosis factor- $\alpha$ (TNF- $\alpha$ )-induced changes of adipokines and oxidative stress in 3T3-L1 adipocytes. J Agric Food Chem 2011; 59(2): 546-551.
8. Slimestad R, Fossen T, Vagen IM. Onions: a source of unique dietary flavonoids. J Agric Food Chem 2007; 55(25): 1006710080.

9. Smith C, Lombard KA, Peffley EB, Liu W. Genetic analysis of quercetin in onion (Allium cepa L.) 'Lady Raider'. Texas J Agric Nat Resource 2003; 16: 24-28.

10. Peluso I, Miglio C, Morabito G, Ioannone F, Serafini M. Flavonoids and immune function in human: a systematic review. Crit Rev Food Sci Nutr 2015; 55(3): 383-395.

11. Vichaponga J, Sookserma M, Srijesdarukb V, Swatsitangc P, Srijaranaia S. High performance liquid chromatographic analysis of phenolic compounds and their antioxidant activities in rice varieties. LWT - Food Sci Technol 2010; 43(9): 1325-1330.

12. Kim OY, Lee SM, Do H, Moon J, Lee KH, Cha YJ, Shin MJ. Influence of quercetin-rich onion peel extracts on adipokine expression in the visceral adipose tissue of rats. Phytother Res 2012; 26(3): 432-437.

13. Kim JH, Shin EH, Lee HY, Lee BG, Park SH, Moon DI, Goo GC, Kwon DY, Yang HJ, Kim OJ, Oh HG. Immunostimulating effects of extract of Acanthopanax sessiliflorus. Exp Anim 2013; 62(3): 247-253.

14. Elmore SA. Enhanced histopathology of the thymus. Toxicol Pathol 2006; 34(5): 656-665.

15. Elmore SA. Enhanced histopathology of the spleen. Toxicol Pathol 2006; 34(5): 648-655.

16. Benítez V, Mollá E, Martín-Cabrejas MA, Aguilera Y, LópezAndréu FJ, Cools K, Terry LA, Esteban RM. Characterization of industrial onion wastes (Allium cepa L.): dietary fibre and bioactive compounds. Plant Foods Hum Nutr 2011; 66(1): 48-57.

17. Lee J, Mitchell AE. Quercetin and isorhamnetin glycosides in onion (Allium cepa L.): varietal comparison, physical distribution, coproduct evaluation, and long-term storage stability. J Agric Food Chem 2011; 59(3): 857-863.

18. Takahama U, Hirota S. Deglucosidation of quercetin glucosides to the aglycone and formation of antifungal agents by peroxidasedependent oxidation of quercetin on browning of onion scales. Plant Cell Physiol 2000; 41(9): 1021-1029.

19. Campos KE, Diniz YS, Cataneo AC, Faine LA, Alves MJ, Novelli EL. Hypoglycaemic and antioxidant effects of onion, Allium cepa: dietary onion addition, antioxidant activity and hypoglycaemic effects on diabetic rats. Int J Food Sci Nutr 2003; 54(3): 241-246.

20. Jung JY, Lim Y, Moon MS, Kim JY, Kwon O. Onion peel extracts ameliorate hyperglycemia and insulin resistance in high fat diet/ streptozotocin-induced diabetic rats. Nutr Metab (Lond) 2011; 8(1): 18.

21. Hertog MG, Hollman PC. Potential health effects of the dietary flavonol quercetin. Eur J Clin Nutr 1996; 50(2): 63-71.

22. Jin HM, Wei P. Anti-fatigue properties of tartary buckwheat extracts in mice. Int J Mol Sci 2011; 12(8): 4770-4780.

23. Chuanlong Z, Xiaoxia Z. Effects of polysaccharides from Pseudostellaria heterophylla on exercise endurance capacity and oxidative stress in forced swimming rats. Sci Res Essays 2011; 6(11): 2360-2365.

24. Lee SP, Mar GY, Ng LT. Effects of tocotrienol-rich fraction on exercise endurance capacity and oxidative stress in forced swimming rats. Eur J Appl Physiol 2009; 107(5): 587-595.

25. Moriura T, Matsuda H, Kubo M. Pharmacological study on Agkistrodon blomhoffii blomhoffii BOIE. V. anti-fatigue effect of the $50 \%$ ethanol extract in acute weight-loaded forced swimmingtreated rats. Biol Pharm Bull 1996; 19(1): 62-66.

26. Pestka $S$. The interferons: 50 years after their discovery, there is much more to learn. J Biol Chem 2007; 282(28): 20047-20051.

27. Park DH, Li YC, Shim J, Xu HD, Li L, Lee MJ, Kwon MS. Biological safety and B cells activation effects of Stephnia delavayi Diels. Mol Cell Toxicol 2009; 5(1): 93-98.

28. Park DH, Park YI, Li YC, Xu HD, Lee JH, Kim YJ, Jang SA, Park SJ, Lee YL, Cho SC, Lee MJ. Biological safety and B cells activation effects of Zanthoxylum schinifolium. Mol Cell Toxicol 
2011; 7(2): 157-162.

29. Seo JW, Cho SC, Park SJ, Lee EJ, Lee JH, Han SS, Pyo BS, Park DH, Kim BH. 1'-Acetoxychavicol acetate isolated from Alpinia galanga ameliorates ovalbumin-induced asthma in mice. PLoS One 2013; 8(2): e56447.

30. Park J, Kim J, Kim MK. Onion flesh and onion peel enhance antioxidant status in aged rats. J Nutr Sci Vitaminol (Tokyo) 2007; 53(1): 21-29.

31. Aggarwal BB. Signalling pathways of the TNF superfamily: a double-edged sword. Nat Rev Immunol 2003; 3(9): 745-756.

32. Lin PL, Plessner HL, Voitenok NN, Flynn JL. Tumor necrosis factor and tuberculosis. J Investig Dermatol Symp Proc 2007; 12(1): $22-25$

33. Cantell K, Hirvonen S, Kauppinen HL, Myllylä G. Production of interferon in human leukocytes from normal donors with the use of Sendai virus. Methods Enzymol 1981; 78(Pt A): 29-38.

34. Shuai K, Schindler C, Prezioso VR, Darnell JE Jr. Activation of transcription by IFN-gamma: tyrosine phosphorylation of a 91-kD DNA binding protein. Science 1992; 258(5089): 1808-1812.
35. Wu CY, Demeure C, Kiniwa M, Gately M, Delespesse G. IL-12 induces the production of IFN-gamma by neonatal human CD4 T cells. J Immunol 1993; 151(4): 1938-1949.

36. Abood WN, Fahmi I, Abdulla MA1, Ismail S. Immunomodulatory effect of an isolated fraction from Tinospora crispa on intracellular expression of INF- $\gamma$, IL-6 and IL-8. BMC Complement Altern Med 2014; 14: 205

37. Ren Z, He C, Fan Y, Guo L, Si H, Wang Y, Shi Z, Zhang H. Immuno-enhancement effects of ethanol extract from Cyrtomium macrophyllum (Makino) Tagawa on cyclophosphamide-induced immunosuppression in BALB/c mice. J Ethnopharmacol 2014; 155(1): 769-775.

38. Gao W, Wu J, Wei J, Pu L, Guo C, Yang J, Yang M, Luo H. Brazilian green propolis improves immune function in aged mice. J Clin Biochem Nutr 2014; 55(1): 7-10.

39. Eloff $J \mathrm{~N}$. Which extractant should be used for the screening and isolation of antimicrobial components from plants? J Ethnopharmacol 1998; 60(1): 1-8. 